\title{
Ascites
}

\section{OP 037 ATTITUDES AND EXPERIENCE OF TRAINEES IN PALLIATIVE MEDICINE TO ABDOMINAL PARACENTESIS}

Morwenna Hitchens, Harriet Bush. Countess Mountbatten House, Southampton, UK

10.1136/bmjspcare-2014-000654.37

Background Abdominal paracentesis is widely used as a symptom control measure for malignant ascites. In the UK, ultrasound guided insertion has become standard practice in some specialist palliative care units. This has resulted in variation in practice between units, inconsistent training opportunities and perceived difficulties for trainees to achieve procedural competencies.

Aim The aim of this study was to establish the views of Palliative Medicine trainees on their experience, competency and the role of ultrasound in paracentesis.

Methods An online questionnaire was sent out to all trainees registered with The Association of Palliative Medicine. 81/230 trainees responded (35\%). $72 \%$ were in their final year of training.

Results In the preceding 12 months $75 \%$ of trainees had performed paracentesis on less than three occasions, 39\% had not put in a single drain. $49 \%$ of trainees anticipated difficulties in achieving the required procedural competence by the end of training due to fewer opportunities, often having to arrange specific clinical attachments to meet the training objectives. In 33\% of units all cases were ultrasound guided yet only 5/81 trainees were trained to use ultrasound. $78 \%$ trainees felt competent to insert a drain without ultrasound although 39\% believed all drains should be placed under ultrasound guidance.

Conclusions Paracentesis is a mandatory skill required to complete training in Palliative Medicine. This study has shown that many units only perform ultrasound guided procedures and yet only $6 \%$ of trainees are trained in this technique. Therefore there are fewer opportunities for training as evidenced by $39 \%$ of trainees not performing paracentesis within 12 months. Most still feel competent to perform paracentesis but this study raises questions regarding maintaining procedural competency and who will train the trainees in the future. If the trend towards ultrasound guidance continues it should become a skill all trainees must learn. 